\title{
Nonhuman Primate Models of Immunosenescence
}

\author{
Andrea Rivera, Maham Rais, Tasha Barr, Nicole Arnold, \\ Suhas Sureshchandra, and Ilhem Messaoudi
}

\begin{abstract}
Due to a dramatic increase in life expectancy, the number of individuals aged 65 and older is rapidly rising. This presents considerable challenges to our health care system since advanced age is associated with a higher susceptibility to infectious diseases due to immune senescence. However, the mechanisms underlying age-associated dysregulated immunity are still incompletely understood. Advancement in our comprehension of mechanisms of immune senescence and development of interventions to improve health span requires animal models that closely recapitulate the physiological changes that occur with aging in humans. Nonhuman primates (NHPs) are invaluable preclinical models to study the underlying causal mechanism of pathogenesis due to their outbred nature, high degree of genetic and physiological similarity to humans, and their susceptibility to human pathogens. In this chapter, we review NHP models available for biogerontology research, advantages and challenges they present, and advances they facilitated. Furthermore, we emphasize the utility of NHPs in characterizing immune senescence, evaluating interventions to reverse aging of the immune system, and development of vaccine strategies that are better suited for this vulnerable population.
\end{abstract}

\footnotetext{
A. Rivera $\bullet$ M. Rais $\bullet$ T. Barr $\bullet$ N. Arnold

Division of Biomedical Sciences, University of California-Riverside, Riverside, CA, USA e-mail: arive019@ucr.edu; maham.rais@ucr.edu; tbarr004@ucr.edu; narno001@ucr.edu

S. Sureshchandra $\bullet$ I. Messaoudi $(\bowtie)$

Department of Molecular Biology and Biochemistry, University of California Irvine, Irvine, CA, USA

e-mail: ssureshc@uci.edu; imessaou@uci.edu
} 


\section{Keywords \\ Nonhuman primates $\bullet$ Aging $\bullet$ Lymphocytes inflammation $\bullet$ Innate immunity}

\section{Contents}

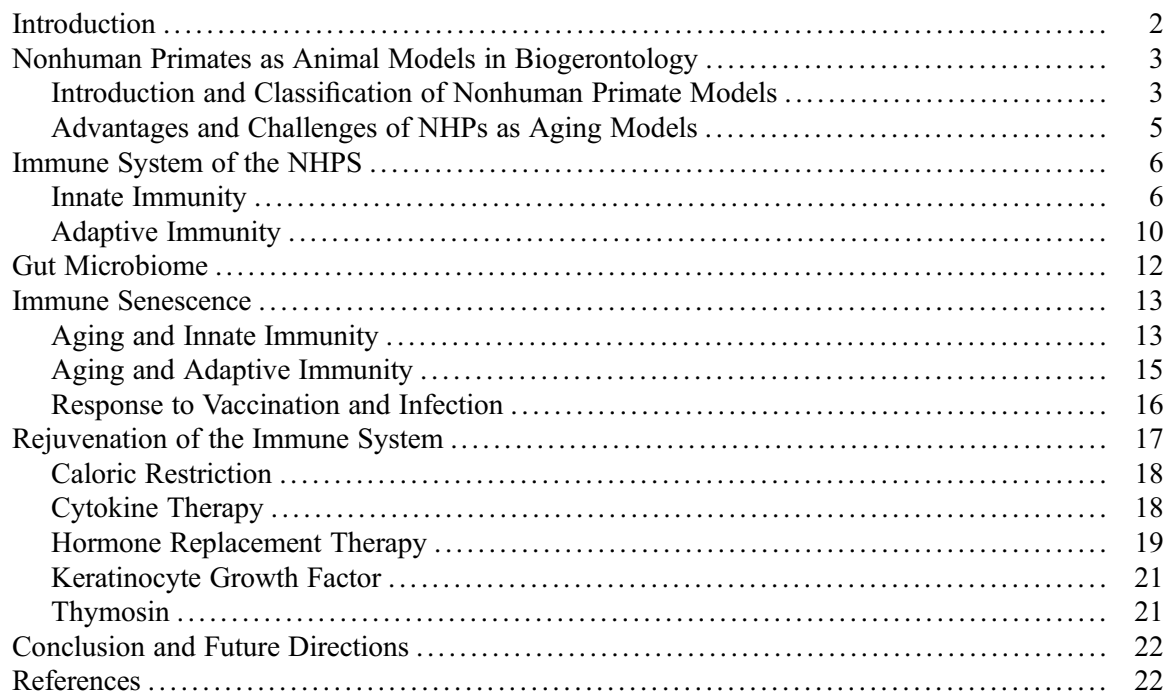

\section{Introduction}

As of 2015, 8.5\% (approximately 617 million) of the world's population are $\geq 65$ years of age, and this number is predicted to increase over $60 \%$ by 2030 and reach 1.6 billion by 2050 (equivalent to $16.7 \%$ of the world total population) (He et al. 2016). The rapid increase of the aging population is due to lower fertility rates and advances in health care leading to longer life expectancies. The rising proportion of older individuals creates a unique challenge for the health care system since despite a decrease in death rates, the incidence of multimorbidities (multiple concurrent health conditions) such as depression, arthritis, hepatitis, neuropathy and hypertension increases with age (He et al. 2016). Moreover, although the leading contributors to morbidity and mortality are noncommunicable diseases, such as cardiovascular disease, lung disease and cancer, older adults, still account for a larger share of infections. The altered immune responses in the elderly are responsible for chronic inflammation and increased susceptibility to infections (Ponnappan and Ponnappan 2011). Furthermore, as of 2013, more than one-third of individuals living with HIV in North America and Western Europe were $\geq 50$ and older (Mahy et al. 2014). Therefore, as the number of elderly individuals rapidly increases, the study of aging and age-related diseases is taking on new urgency. Biomedical research in this area requires the use of animal models that faithfully recapitulate 
different physiological aspects of aging in humans. In this chapter, we focus on the utility of the nonhuman primate models to study the effects of aging on immune fitness.

\section{Nonhuman Primates as Animal Models in Biogerontology}

\section{Introduction and Classification of Nonhuman Primate Models}

Understanding mechanisms of cellular senescence heavily depends on the use of appropriate animal models to elucidate the underlying causal mechanisms. To date, most of our understanding of the biological changes that occur with aging has come from studies utilizing rodent models. Advantages of rodent models include an extensive set of reagents, the presence of genetically modified strains, and a short lifespan allowing for longevity studies of short duration. However, rodents separated from humans more than 70 million years ago making them less ideal for translational research. Rodent models also present numerous challenges when investigating the immune system. For example, the peripheral immune system of rodents continues to develop after birth, in contrast to humans, which are born with a fully populated lymphoid immune system including various $\mathrm{T}$ - and B-cell subsets, specialized lymphoid tissues, as well as the ability to respond to wide range of antigens (Hein and Griebel 2003).

In contrast, nonhuman primates (NHPs) share significant genetic and physiological homology as well as behavioral characteristics with humans. The outbred nature of NHPs enables rigorous validation of research findings that goes beyond the proof of principle provided by rodent models. Furthermore, co-morbidities in aged NHPs closely mirror those seen in humans including the development of age-related diseases such as perturbed sleep-wake cycles, cognitive decline, cataracts, macular degeneration, loss of motor skills, impaired memory acquisition, social motivation shifts, diabetes, hypertension, osteoporosis, pancreatic and neurologic amyloid deposition, and atherosclerosis (Nadon 2006; Shively and Clarkson 2009; Almeling et al. 2016; Phillips et al. 2014). These diseases only appear in modified strains and various forms of genetic manipulation do not always recapitulate the clinical picture. In contrast, the appearance of these diseases in NHPs, especially atherosclerosis, is increased with age and with the consumption of a Western diet, similar to what has been described in humans (Nadon 2006; Shively and Clarkson 2009). Moreover, as described for humans, female and male rhesus macaques undergo menopause and andropause, respectively (Weinbauer et al. 2008; Urbanski and Sorwell 2012). NHPs are also susceptible to human pathogens or closely related simian counterparts (Kennedy et al. 1997). Moreover, NHPs are consistently more predictive of drug pharmacokinetics in humans than in rodent models (Ward et al. 2005). Finally, NHPs include several long-lived species. Therefore, NHPs offer a robust translational model to study various aspects of human aging by allowing us to conduct mechanistic studies under controlled conditions in an outbred species that closely mimics 
human biology. Their close evolutionary relationship to humans ensures high fidelity models with unique predictive value for human diseases.

NHPs can be classified into two broad groups: old world monkeys (e.g., macaques and baboons), which are native to Asia and Africa, and new world monkeys (e.g., marmosets, squirrel, and spider monkeys) which are native to South and Central America (Rogers and Gibbs 2014). Old world monkey species have the closest evolutionary relationship to humans (Brosnan et al. 2012), while New World monkeys are more phylogenetically distant from Homo sapiens. It is estimated that New World monkeys diverged over 30 million years ago whereas Old World monkeys diverged 15 million years ago (Kennedy et al. 1997). Indeed, a study utilizing a coordination game to better understand cognitive mechanisms found Old World monkeys acted more similar to humans than New World monkeys (Brosnan et al. 2012). Moreover, in contrast to Old World monkeys, very few reagents have been validated for cross-reactivity with New World monkey cells. Nonetheless, this group does present some advantages such as their smaller size, ease of handling, and reduced risk of zoonotic disease transmission (Salmon 2016). Consequently use of the marmoset is becoming increasingly more common (Salmon 2016; Ross et al. 2012). Recent studies have highlighted their utility as a model for a number of age-related diseases including Parkinson's disease, diabetes, cardiovascular disease, cancer, and renal disease (Salmon 2016). However, macaques remain the preferred NHP resource for biomedical research. The two most commonly used NHP models in biomedical research are the rhesus macaque (Macaca mulatta) and the cynomolgus or long-tailed macaque (Macaca fascicularis). Chimpanzees and bonobos (evolutionarily nearest living relatives of humans) would most faithfully represent human aging. However, practical and ethical considerations, such as their status as endangered species and their long life span (up to 60 years in captivity), make these less appealing for aging research. In 2015, the NIH ended all support for chimpanzee research under the endangered species protection act.

The rhesus macaque (Macaca mulatta) genome shares 93.54\% homology to humans (Rogers and Gibbs 2014) with a comparable GC-content $(40.71 \%$ vs. $40.74 \%$ ) (Rhesus Macaque Genome et al. 2007). The majority of protein-coding genes have homologs among humans and Old World monkeys sequenced to date; however, some gene families have expanded or contracted in individual lineages. One study estimates 1,358 genes as new duplications in the rhesus genome compared to humans. The HLA gene cluster, for example, which is critical for response to pathogens as well as other immunological processes, is expanded in macaques relative to humans (Rogers and Gibbs 2014). The density of SNPs is also significantly higher in rhesus macaques compared to humans. Including singletons, about 14 million single nucleotide variants were found in the rhesus macaque genome compared to 3.6 million SNPs (including singletons) per human individual according to the 1000 Genomes Project (Rogers and Gibbs 2014).

Macaques are also long-lived, suggesting that similar patterns of aging may have evolved in these closely related primate species. Animals are categorized as young adults ( $<15$ years old), middle-aged (15-20 years old), old (20-25 years old), and senile ( $>25$ years old), with the oldest animal living until 36 years (Tigges et al. 
1988). Early observations of rhesus macaque colonies indicated a median survival time of about 16 and 18 years for males and females, respectively (Tigges et al. 1988). However, later studies observed $50 \%$ survivorship at about 24 years for males and 20 years for females (Dyke et al. 1986). This was confirmed in more recent longterm study that reported an average lifespan of 25 years and a maximum lifespan of 40 years for rhesus macaques (Bodkin et al. 2003). Because the oldest human survived to over 120 years, rhesus macaques have a maximum lifespan approximately one-third that of humans.

\section{Advantages and Challenges of NHPs as Aging Models}

As with all experimental animal models, NHPs present several advantages and challenges. Major strengths include their genetic, physiological, and behavioral similarity to humans as well as their susceptibility to human disease and pathogens as discussed above. Furthermore, NHPs can be maintained in carefully controlled environments (e.g., photoperiod, temperature, diet, and medication) reducing confounding factors and self-selection bias that is often unavoidable in human clinical trials (VandeBerg and Williams-Blangero 1997). The use of NHPs is also advantageous because similar techniques (e.g., activity recording, MRI, CT scans, PET scans, and telemetry) can be deployed. Another advantage of NHPs is their larger size, which allows for longitudinal and cross-sectional assessments of multiple organ systems using critical surgical procedures such as bronchoalveolar lavages, laparoscopic surgeries, and punch biopsies (Tardif et al. 2013). These advantages provide the possibility of testing new drugs, vaccines, and interventions in a truly translational model.

However, the longer lifespan of NHPs compared to other laboratory animals is also a challenge when using NHPs in biogerontology research. While a 25 -year lifespan is considerably shorter than that of humans, it is still prohibitive for longitudinal studies. Moreover, limited availability of aged NHPs, the high costs associated with NHP research, and the specialized housing requirements can be prohibitive for most researchers. Finally, the ever-increasing level of regulation concerning the use of NHPs in research can be a major burden. To overcome some of these limitations, the National Institutes of Health (NIH) has developed specialized resources to encourage and promote the use of NHP models in aging research.

The NIH supports seven National Primate Research Centers (NPRCs) that provide an effective infrastructure to supply and house NHPs for the benefit of research into human diseases. Macaques represent the majority of the NHPs housed at the NPRCs, but other old world species such as African green, sooty mangabey, and baboons as well as several New World species such as marmosets are also housed at the NPRCs. The National Institute on Aging (NIA) has made significant investments in resources to facilitate the use of NHP in aging research. These include the maintenance of several colonies of aged macaques in the Primate Aging Study, as well as the NHP tissue bank, which has archives of frozen and fixed tissues collected from aged rhesus macaques from various colonies (Nadon 2006). In addition, the 
primate aging database (PAD) was developed via a collaboration between NIH intramural and extramural programs (Nadon 2006). This database brings together blood chemistry parameters and body weights collected from thousands of monkeys at NPRCs. The data are mostly generated from healthy animals, which can limit the utility of the findings obtained by studying these animals. The NIA has also established a Cell Bank, which contains cell lines from various NHP species as well as DNA extracted from young and aged individuals from different NHP species. These resources are available to the research community in order to promote investigations that can benefit from the use of the aged NHP model.

\section{Immune System of the NHPS}

The immune system protects the body by eliminating microbial threats while limiting damage to the host. This is achieved by the coordinated action of two subsystems: the innate and adaptive immune system. The major difference between these two branches is that innate immunity broadly recognizes antigens using germline-encoded receptors, whereas adaptive immunity is tailored to detect specific pathogens through a highly diverse set of receptors that is generated via recombination and somatic mutation. Another distinguishing feature is the ability of the adaptive immune system to develop immunological memory, which upon re-encounter to the same antigen results in increased efficiency of responding cells. In this section of the chapter, we will summarize our understanding of both the innate and adaptive immune system of rhesus macaques, while reviewing similarities and differences to human immune system.

\section{Innate Immunity}

The innate immune system is the first line of defense against pathogens and is composed primarily of neutrophils, monocytes/macrophages, dendritic cells (DCs), and natural killer (NK) cells. These innate cells use germline-encoded receptors to recognize conserved pathogen-associated molecular patterns (PAMPs), and thus, these receptors are referred to as pathogen recognition receptors (PRRs). The most well-known families of PRRs are Toll-like receptors (TLRs), retinoic acid-inducible gene (RIG-I) like RNA helicases (RLHs), and Nod-like receptors (NLRs) including NODs and NALPs. After recognition of foreign antigens, PRRs initiate intracellular signaling resulting in the production of antimicrobial and antiviral molecules that inhibit pathogen replication and spread. The innate immune branch plays a critical role in activating the adaptive immune response via antigen processing and presentation as well as production of cytokines and chemokines. This section will focus on monocytes/macrophages, DC, and NK cell function in rhesus macaques. Since limited information is available for NHP neutrophils, basophils, and eosinophils, they will not be discussed here. 


\section{Monocytes and Dendritic Cells}

Monocytes and DCs are scavenging cells that can ingest and destroy infectious agents while also serving as professional antigen-presenting cells (APC) responsible for processing and presenting foreign antigen peptides to $\mathrm{T}$ cells, thereby linking innate and adaptive immunity. In humans, three subsets of monocytes have been identified by the differential expression of CD14 and CD16 (Wong et al. 2011). Classical monocytes, which mainly function in phagocytosis, can be identified as $\mathrm{CD} 14^{+} \mathrm{CD} 16^{-}$and constitute the majority of monocytes under resting physiological conditions. Intermediate monocytes express high levels of both CD14 and CD16 $\left(\mathrm{CD} 14^{+} \mathrm{CD} 16^{+}\right)$and have a higher capacity to release IL1 $\beta$ and TNF $\alpha$ in response to LPS compared to classical monocytes (Wong et al. 2011). Nonclassical monocytes are identified as $\mathrm{CD} 14^{-} \mathrm{CD} 16^{+}$and are major producers of TNF $\alpha$ in addition to IL12 and nitric oxide (NO) (Wong et al. 2011). Rhesus macaques exhibit the same distribution and function of these three subsets of monocytes that can also be differentiated by CD14 and CD16 expression (Fig. 1; Sugimoto et al. 2015). Additionally, viral infection with simian varicella virus (SVV) or simian immunodeficiency virus (SIV) increased frequency of intermediate and non-classical monocytes (Kim et al. 2010; Haberthur et al. 2014). Moreover, following SIV infection in rhesus macaques, classical monocytes expressed the highest levels of TNF $\alpha$, followed by intermediate monocytes, whereas nonclassical monocytes did not express TNF $\alpha$ (Kim et al. 2010).

Human DCs are identified based on the expression of class II major histocompatibility complex (MHC-II) and absence of $\mathrm{T}, \mathrm{B}$, and macrophage markers $\left(\mathrm{CD}{ }^{-} \mathrm{CD} 20^{-} \mathrm{CD}^{-} 4^{-} \mathrm{HLA}^{-} \mathrm{DR}^{+}\right)$and can be further subdivided into either myeloid DCs (mDC; CD11 $\mathrm{c}^{+} \mathrm{CD} 123^{-}$), or plasmacytoid DCs (pDC; CD11 ${ }^{-} \mathrm{CD} 123^{+}$) (O'Keeffe et al. 2015). Myeloid DCs process and present antigens to naïve $\mathrm{T}$ cells and produce IL-12 while producing limited amounts of antiviral cytokine IFN $\alpha$ (O'Keeffe et al. 2015). In contrast, pDCs are able to produce large amounts of IFN $\alpha$ in response to viral infection (O'Keeffe et al. 2015). Myeloid DCs and pDCs can be identified in rhesus macaques using the same surface markers as described in humans (Autissier et al. 2010) and are functionally similar (Fig. 1). Viral infections result in mobilization and recruitment of $\mathrm{pDCs}$ and the generation of a robust type I IFN response (Haberthur et al. 2014; Chung et al. 2005; Teleshova et al. 2004a; Harris et al. 2010). CD1c has also been used as a marker of cynomolgus macaque $\mathrm{mDCs}$, but are not co-expressed with CD11c; therefore, expression of CD1c and $\mathrm{CD} 11 \mathrm{c}$ may be required to avoid underestimating $\mathrm{mDC}$ numbers in macaques (Autissier et al. 2010; Malleret et al. 2008). Less differentiated DCs (ldDC; $\mathrm{CD} 11 \mathrm{c}^{-} \mathrm{CD} 123^{-}$) have been identified in pregnant women, cord blood, and patients with rheumatoid arthritis (Aldebert et al. 2007; Dombrecht et al. 2006). This subtype has also been described in rhesus macaques (CD11 $\mathrm{c}^{-} \mathrm{CD} 123^{-}$), and its frequency is altered following radiation and immunosuppressive treatment (Meyer et al. 2015). Importantly, ldDCs have not been described in mice.

The expression of TLRs among different DC subsets is identical between humans and macaques but differs from murine DCs (Ketloy et al. 2008). Rhesus macaque 


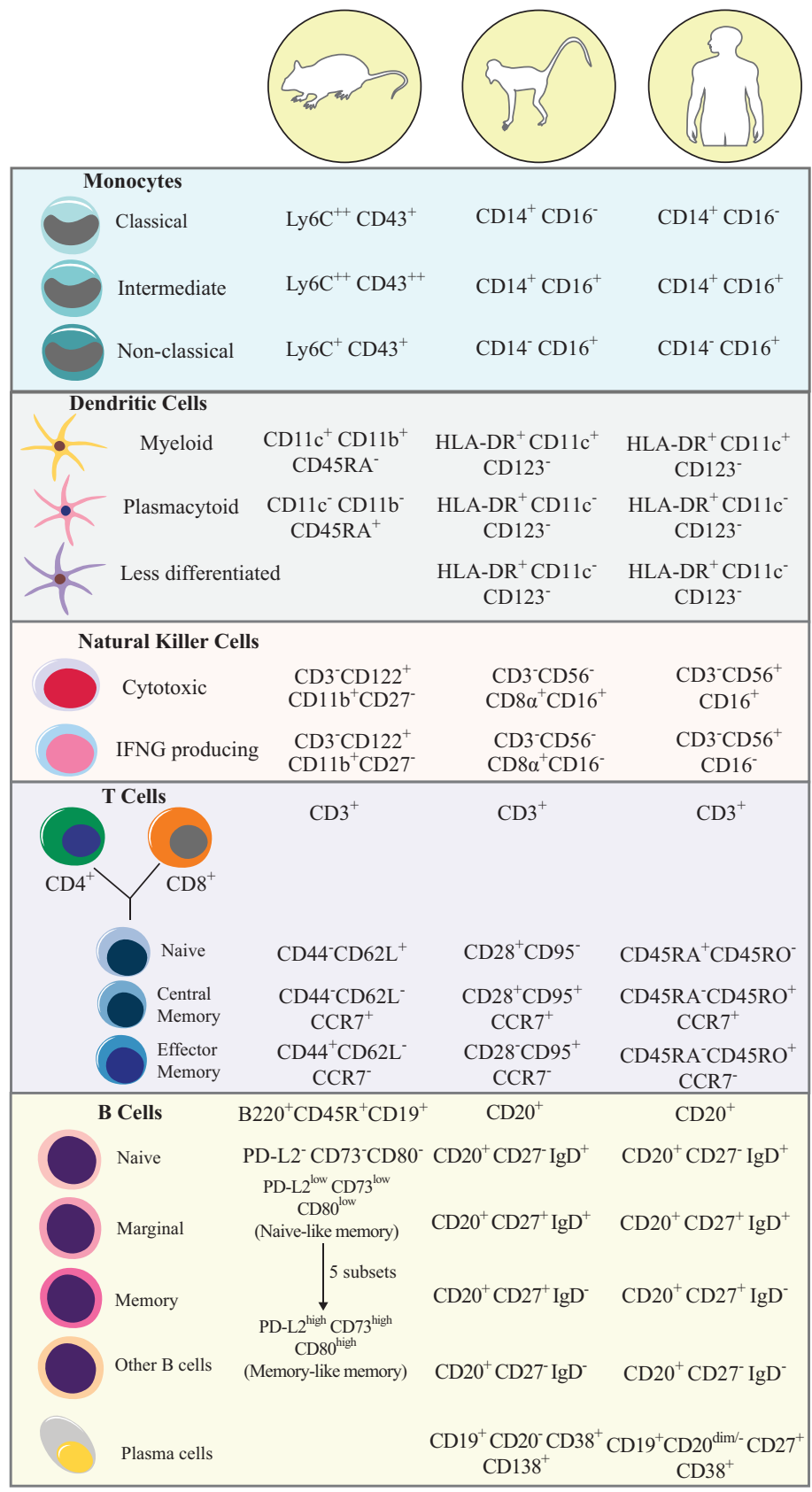

Fig. 1 Nonhuman primates (NHP) and human immune cells are identified using similar markers. Cells of the innate and adaptive branches are identified using similar cell surface markers in humans and NHPs. In contrast, comparable subsets are identified using different set of markers in rodents 
mDCs express TLR3, 4, 7, and 8 and upregulate co-stimulatory molecules CD40 and CD86 upon TLR stimulation (Ketloy et al. 2008). Similarly, pDCs express TLR7 and TLR9, which respond to viral infection by initiating the production of IFN $\alpha$ and IL-12 in addition to upregulation of CD86 (Chung et al. 2005; Teleshova et al. 2004a; Ketloy et al. 2008). Furthermore, pDCs in both humans and rhesus macaques constitutively express high levels of IRF7, which is critical in inducing IFN $\alpha$ transcription (Chung et al. 2005). In contrast, TLR8 is not functional in mice and TLR9 is broadly expressed on several cell types including DCs, B cells, macrophages, and monocytes (Edwards et al. 2003). These differences provide the justification needed for the use of NHP to evaluate adjuvants in vivo. Finally comparable methods have been developed to mobilize circulating DCs in vivo using either the hematopoietic growth factor Flt3 ligand (Flt3L) (Teleshova et al. 2004b) or ProGP, a chimeric molecule of Flt3-L and G-CSF can mobilize $\mathrm{mDC}$ and $\mathrm{pDC}$ in NHPs (Koopman et al. 2005).

\section{NK Cells}

NK cells can recognize missing self or altered self and eliminate tumors and virus infected cells. NK cells also bridge innate and adaptive immunity through the secretion of specific cytokines and chemokines that in turn modulate the kinetics and magnitude of a $\mathrm{T}$ cell response. Human NK cells are identified as $\mathrm{CD}^{-}{ }^{-} \mathrm{CD} 56^{+}$ and can be further subdivided based on the expression of CD16 (Lanier 2008). CD $16^{+}$NK cells make up a majority of blood and spleen NK cells $(\sim 90 \%)$ and are highly cytotoxic, secreting moderate amounts of inflammatory cytokines. CD16 NK cells on the other hand exhibit poor cytotoxicity and secrete large amounts of inflammatory cytokines (Lanier 2008). Characterization of NK cells differs slightly between NHPs and humans (Fig. 1). First, CD56 is a marker for monocytes not NK cells in rhesus macaques (Carter et al. 1999). Second, unlike human NK cells, macaque NK cells express high levels of CD8 $\alpha$ (Webster and Johnson 2005). Therefore, NK cells in NHPs are identified as $\mathrm{CD}^{-} \mathrm{CD} 8 \alpha^{+}$but can still be divided into the $\mathrm{CD}_{16}{ }^{+}$cytolytic population and the minor $\mathrm{CD} 16^{-}$cytokine-producing population as described for humans.

The balance of signals generated by either inhibiting and activating receptors determines NK-mediated activity (Lanier 2008). Inhibitory NK receptors, which can be divided into either killer immunoglobulin-like receptors (KIRs) or C-type lectin receptors, interact with specific allelic forms of MHC-I molecules and inhibit NK cell killing (Lanier 2008). However, if signaling via inhibitory receptors is absent, NK cell-mediated lytic activity can be triggered via activating receptors such as NKp44, NKp46, NKp30, or NKG2D by cell surface ligands on pathogen-infected or tumor cells (Lanier 2008). Inhibitory NK receptor CD94/NKG2A, as well as activating receptors $\mathrm{NKp} 80$ and NKG2D in rhesus macaques and humans, exhibits a high degree of sequence (Mavilio et al. 2005) and functional homology (Mavilio et al. 2005).

Clinical studies have suggested that NK cells can impact the progression and severity of several viral infections, notably human immunodeficiency virus (HIV) (Alter and Altfeld 2009). The importance of NK cell function in host response to 
HIV was investigated using the SIV model (Choi et al. 2008). Rhesus macaques depleted of NK cells before SIV infection using a humanized monoclonal antibody against CD16 experienced higher peak viral loads, but no differences were detected during the chronic phase of disease. Furthermore, in macaques already infected with SIV, administration of the human anti-CD16 monoclonal antibody did not alter set viral loads (Choi et al. 2008), suggesting that NK cells do not modulate severity of SIV/HIV infection. These studies represent an example of how the role of specific immune cells can be interrogated in a robust translational model of human disease to advance our understanding of mechanisms of microbial pathogenesis.

\section{Adaptive Immunity}

Adaptive immune responses are mediated by $\mathrm{T}$ and $\mathrm{B}$ cells, which express a highly diverse set of receptors that are generated through recombination and somatic mutations. Adaptive immunity also develops immunological memory, which results in an enhanced effector response upon re-exposure to the same antigen.

\section{T-Cell Compartment}

$\mathrm{T}$ cells are responsible for cell-mediated responses against pathogens and stem from progenitor cells in the thymus. T cells utilize $\mathrm{T}$ cell receptors (TCRs) to recognize antigens in the form of small peptides bound to either MHC-I or MHC-II molecules. CD4 $\mathrm{T}$ cells, which are also known as helper $\mathrm{T}$ cells, recognize peptides bound to MHC-II and secrete cytokines important in differentiating B cells into antibodyproducing plasma cells and the development of cytotoxic (CD8) T cells. CD8 T cells recognize peptide bound to MHC-I and upon recognition are able to kill cells containing intracellular pathogens or tumor cells. The highly diverse TCR repertoire is generated through: (1) recombination of different TCR variable (V), diversity (D), joining (J), and constant (C) segments of the TCR chain; (2) random nucleotide additions and deletions at the junctions of segments; and (3) pairing of different chains. There are $2.5 \times 10^{7}$ possible TCR combinations in the naïve human T cell repertoire (Arstila et al. 2000). Analysis of rhesus macaque TCR diversity revealed TCR genes shared significant homology with their human homologues (Thiel et al. 1995; Greenaway et al. 2009). Specifically, sequencing of 18 rhesus macaque TCR $\alpha$ (TCRA) chain clones revealed 12 TCRAV and 16 TCRAJ regions corresponded closely to human counterparts, with variations occurring at $5^{\prime}$ ends (Thiel et al. 1995). Furthermore, in the same study, sequenced cDNA of the TCRAC1 gene of rhesus macaque showed extensive conservation to the human sequence $(93.4 \%)$. Comparison between rhesus and human TCR $\beta$ (TRB) genes showed $92.9 \%$ similarity of (Greenaway et al. 2009). Specifically 72 TRBV, 2 TRBD, and 14 TRBJ genes extracted from the rhesus macaque genome had an average similarity of $92.2 \%, 93.9 \%$, and $96.1 \%$ to their corresponding human homologs, respectively (Greenaway et al. 2009).

MHC molecules present a diverse pool of peptides for TCR recognition. Humans have 3 MHC class I loci: HLA-A, B, and C; and three MHC-II loci: HLA-DP, DQ, 
and DR. Each locus can encode multiple alleles and polymorphism is allocated in the peptide-binding regions (Hughes and Yeager 1998). There are genetic differences in MHC loci between macaques and humans. Although rhesus macaques have three MHC-II loci: DP, DQ and DR, they only have two MHC-I loci: A and B (Doxiadis et al. 2007). Furthermore, sequencing of a complete rhesus macaque MHC locus revealed major expansion from six human MHC-I genes to as many as 22 active MHC-I genes in rhesus. Moreover, there were high levels of genetic polymorphism found over most of the MHC region with as high as a 10-fold higher sequence divergence from humans (Daza-Vamenta et al. 2004).

Markers that define human $\mathrm{T}$ cell subsets can also be used in rhesus macaques (Fig. 1). In both humans and NHPs, T cells can be identified based on the expression of $\mathrm{CD} 3$ and divided into $\mathrm{CD} 4^{+}$and $\mathrm{CD} 8^{+} \mathrm{T}$ cells. In humans, naïve $\mathrm{T}$ cells are defined as $\mathrm{CD}^{2} 5 \mathrm{RA}^{+} \mathrm{CD} 45 \mathrm{RO}^{-}$and after antigen encounter, memory $\mathrm{T}$ cells gain expression of CD45RO while losing expression of CD45RA (Mahnke et al. 2013). CD45RA has also been used to identify naïve T cells in rhesus macaques; however, CD45RA expression on antigen experienced cells is common in macaques (Pitcher et al. 2002) and CD45RO can only reliably identify memory $\mathrm{CD}^{+} \mathrm{T}$ cells in macaques (Wang et al. 2008). Therefore, most macaque studies rely on the expression of co-stimulatory molecule CD28 and Fas receptor CD95 to delineate three major subsets: naïve $\left(\mathrm{Na} ; \mathrm{CD} 28^{+} \mathrm{CD} 95^{-}\right)$, central memory $\left(\mathrm{CM} ; \mathrm{CD} 28^{+} \mathrm{CD} 95^{+}\right)$, and effector memory (EM; CD28 ${ }^{-} \mathrm{CD}^{+} 5^{+}$) (Pitcher et al. 2002). More precise differentiation of peripheral memory $\mathrm{T}$ cells can be made by the expression of chemokine receptor CCR7: $\mathrm{CD} 28^{-} \mathrm{CD} 95^{+} \mathrm{CCR} 7^{-}$represents terminally differentiated $\mathrm{EM} \mathrm{T}$ cells, and $\mathrm{CD} 28^{+} \mathrm{CD} 95^{+} \mathrm{CCR} 7^{+}$delineate $\mathrm{CM}$ T cells, while $\mathrm{CD} 28^{+} \mathrm{CD} 95^{+} \mathrm{CCR} 7^{-}$ and $\mathrm{CD} 28^{-} \mathrm{CD} 95^{+} \mathrm{CCR} 7^{+}$cells represent transitional populations (Picker et al. 2006). The use of CD28, CD95, and CCR7 can also be used to delineate naïve and memory subsets in humans as well (Mahnke et al. 2013).

The survival of naïve T cells is dependent on IL-7 and MHC contact, both of which induce homeostatic proliferation of these cells. In contrast, memory T cells do not require MHC contact and instead require IL-7 and IL-15 for survival (Surh and Sprent 2008). T cell homeostasis in NHPs has similar requirements as described for humans and rodents. Genes encoding rhesus IL-7 and IL-15 have high genetic (96\%), amino acid and functional similarities with humans and rodent homologues (Ansari et al. 2004). Furthermore, the administration of recombinant rhesus IL-7 induced proliferation of naïve and central memory T cells, while IL-15 resulted in increased frequency (Villinger et al. 2004) and proliferation of EM T cells (Picker et al. 2006; Villinger et al. 2004). One difference between mouse and humans is that while IL-7 is critical for both T and B cell survival in mice, it is required only for T cell survival in humans (Roifman et al. 2000; Surh and Sprent 2008). Similarly, IL-7 is required for T cell survival in rhesus macaques (Vassena et al. 2012).

\section{B-Cell Compartment}

$\mathrm{B}$ cells are responsible for humoral responses against pathogens. They stem from progenitor cells in the bone marrow, which differentiate into mature, naïve B cells following rearrangement of heavy $(\mathrm{H})$ and light $(\mathrm{L})$ chains, which make up the B cell 
receptor (BCR) (Crowley et al. 2008). BCR H and L chain variable regions are highly conserved between humans and macaques, which has facilitated $\mathrm{B}$ cell maturation studies in NHPs (Bible et al. 2003; Ermert et al. 1995; Link et al. 2002). Human peripheral $\mathrm{B}$ cells are identified by CD20 expression and can be further distinguished based on the expression of CD27 and IgD into naïve B cells $\left(\mathrm{CD} 27^{-} \mathrm{IgD}^{+}\right)$, memory B cells $\left(\mathrm{CD} 27^{+} \mathrm{IgD}^{-}\right)$, and marginal zone B cells $\left(\mathrm{CD} 27^{+} \operatorname{IgD}{ }^{+}\right)$, which represent a transitional memory population (Bar-Or et al. 2001). Double negative memory $\mathrm{B}$ cells $\left(\mathrm{CD}_{2} 7^{-} \mathrm{IgD}{ }^{-}\right)$have been identified in healthy patients and were found to increase in individuals with autoimmune disease (Wei et al. 2007). These markers can be used to delineate B cells and their subsets in macaques (Fig. 1; Haberthur et al. 2014).

Upon activation in lymphoid tissues, B cells undergo proliferation and differentiate into Ig-secreting plasma cells or long-lived memory B cells (Caraux et al. 2010). Isotype class switching (i.e., IgM to $\operatorname{IgG}$, IgA, or $\operatorname{IgE}$ ) and somatic hypermutation also occur, resulting in antigen-experienced memory B cells that can produce high affinity antibodies (Caraux et al. 2010). Similar processes have been described in macaques. For instance, during SIV infection, germinal centers support antigen-driven somatic hypermutation of antibodies that follows the rate of nucleotide substitution and selection that is very similar as described for humans infected with HIV (Margolin et al. 2006; Kuhrt et al. 2010). Activation of rhesus macaque B cells results in the upregulation of co-stimulatory molecules CD40, CD80, and CD86 as observed in humans. In humans, circulating antibody secreting plasma cells are defined as $\mathrm{CD} 19^{+} \mathrm{CD} 20^{\mathrm{dim} /-} \mathrm{CD} 27^{+} \mathrm{CD} 38^{+}$(Caraux et al. 2010). In rhesus macaques, plasma cells have a slightly different phenotype compared to humans and show a $\mathrm{CD} 19^{+} \mathrm{CD} 20^{-} \mathrm{CD} 38^{+} \mathrm{CD} 138^{+}$phenotype (Fig. 1; Neumann et al. 2015).

\section{Gut Microbiome}

The gut microbiome, a community of microbes that have co-evolved with the host in a mutualistic relationship, protects against enteric infection through competition for resources and by stimulating the development of the immune system and mucosal barrier (Kaiko and Stappenbeck 2014). Microbial cells were previously thought to outnumber mammalian cells $\sim 10: 1$, but revised estimates believe it is closer to 1:1 (Sender et al. 2016). The healthy human microbiome is dominated by Bacteroidetes and Firmicutes, with Bacteroides being the most abundant and prevalent bacterial genus in the GI tract (Lloyd-Price et al. 2016). Only one study to date has characterized biogeography of the rhesus intestinal mucosal and lumenal microbiomes using samples from 15 healthy older females (18 \pm 3.5 years) (Yasuda et al. 2015). Analysis of fecal material along with paired lumenal and mucosal samples from ten sites distal to the jejunum revealed that macaque stool microbiota is representative of the composition present in the colonic lumen and mucosa. Similar to the composition seen in humans, the rhesus macaque intestine is primarily colonized by the Bacteroidetes, Firmicutes, and Proteobacteria phyla. In contrast to humans, Actinobacteria and Verrucomicrobia are rare in rhesus macaques, while Spirochaetes and the genus Helicobacter were more abundant. A second study that analyzed gut 
microbial communities and diet in multiple primate species living in the wild, in a sanctuary, and in full captivity also found that captivity and loss of dietary fiber in NHPs are associated with loss of native gut microbiota and convergence toward the western human microbiome (Clayton et al. 2016).

\section{Immune Senescence}

Aging results in several structural and functional changes in the immune system and is clinically associated with increases in the frequency and severity of infectious diseases and incidences of cancer, chronic inflammatory disorders, and autoimmunity. This general dysregulation in immune system function is referred to as immune senescence (Weiskopf et al. 2009). Involution of the thymus and diminished output of naïve $T$ cells are perhaps the most recognized changes in the immune system with age. However, the effects of aging on the immune system are widespread, extending from hematopoietic stem cells and lymphoid progenitors to mature lymphocytes in secondary lymphoid organs. In this section of the chapter, we will summarize our current understanding of age-related changes in both innate and adaptive immunity of the rhesus macaque, while emphasizing parallels with the human immune system. We will also review the utility of the NHP model in developing and testing immunorestorative approaches.

\section{Aging and Innate Immunity}

While many responses in the innate immune system are diminished with aging, there is substantial evidence for age-associated hyper-reactivity of innate immunity as well (Weiskopf et al. 2009; Shaw et al. 2010). More specifically, studies have suggested that aging is associated with increased permeability of mucosal barriers, decreased phagocytic and chemotactic activity of phagocytic cells, reduced NK cell cytotoxicity, and altered production of soluble mediators (Weiskopf et al. 2009). These alterations could lead to increased pathogen invasion and poor activation of the adaptive immune response mediated by $\mathrm{T}$ and B-lymphocytes. Absolute numbers of NK cells increase with age, reflecting an increase in CD56 $6^{-}$cells (Shaw et al. 2010), but NK cell cytotoxicity and their ability to produce cytokines and chemokines such as RANTES, MIP1 $\alpha$, and IL-8 upon activation are reduced (Shaw et al. 2010). Similarly, the investigators at the Wisconsin National Primate Research Center have demonstrated that a decrease in NK cell cytolytic activity correlates strongly with a shortened lifespan in rhesus macaques, thereby serving as a useful biomarker for longevity (Coe and Ershler 2001).

Aging results in defects in TLR-7 and TLR-9-induced IFN- $\alpha$ production by $\mathrm{pDCs}$ (Jing et al. 2009). Furthermore, an age-associated defect in LPS-induced IL-12 production by $\mathrm{mDCs}$ was reported (Jing et al. 2009). A generalized age-associated decline in the production of TNF- $\alpha$, IL- 6 , and the $\mathrm{p} 40$ subunit shared by IL-12 and IL-23 following TLRs $1 / 2,2 / 6,3,4,5$, and 8 stimulation was strongly associated with reduced influenza vaccine antibody response (Panda et al. 2010). In contrast, 


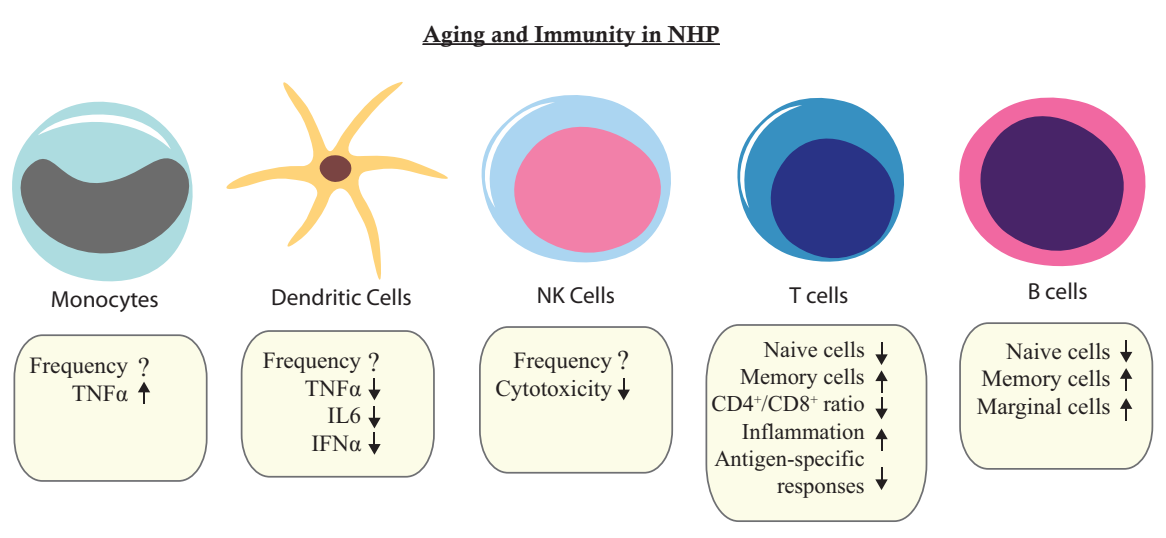

Fig. 2 Age-related changes in NHP immune cells. Several function and phenotypic changes have been reported in cells of the innate and adaptive branches in NHPs. However, several gaps remain in our understanding of immune senescence in this valuable translational model

recent studies have shown increased production of TNF- $\alpha$, IL- 6 , and IFN $\alpha$ by monocyte-derived DCs in response to LPS and to self-DNA from old compared to young subjects (Agrawal et al. 2009). Comparably, in rhesus macaques, with the exception of increased TNF $\alpha$ by monocytes in response to LPS, TNF $\alpha$, IL-6, and IFN $\alpha$ production by DCs in response to stimulating with agonists of TLR4, TLR2/6, and TLR7/9 declined with age (Fig. 2; Asquith et al. 2012). In addition, the global analysis of PBMC pattern recognition receptor (PRR) expression revealed significantly reduced expression of absent in melanoma 2 (AIM2) and retinoic acidinducible gene I (RIG-I) in aged compared to the adult macaques (Asquith et al. 2012). RIG-I is reported to mediate antiviral responses against a number of clinically significant pathogens such as influenza type A and West Nile Virus (Kato et al. 2006), which cause increased morbidity and mortality in the elderly (Gubler 2007; La Gruta et al. 2007). AIM2 is thought to respond to the dsDNA of bacteria and viruses (Rathinam et al. 2010). Therefore, it will be of interest to see whether diminished RIG-I or AIM2 expression in humans may contribute to enhanced susceptibility to these pathogens in the elderly.

In humans, aging of the immune system is also associated with an increase in the systemic inflammatory cytokines, especially IL-6 and TNF $\alpha$ (De Martinis et al. 2005). This phenomenon, often referred to as "inflammaging," is hypothesized to contribute to the development and/or aggravation of several chronic diseases such as Alzheimer's and osteoporosis (De Martinis et al. 2005). Both IL-6 and IL-1RA levels are increased in older macaques, which is consistent with the concept of "inflammaging" (Asquith et al. 2012). In contrast, IL-15 and IL-12 levels decrease with age (Asquith et al. 2012). Given that IL-15 modulates effector T cell activity (Surh and Sprent 2008) and plays an important role in maintaining central and effector memory T cells (Surh and Sprent 2008), it is interesting that these subsets accumulate with age, despite declining levels of IL-15. Additional studies showed that mitogen stimulation of whole blood or purified peripheral blood mononuclear 
cell (PBMC) from rhesus macaques displayed an age-related increase in IL-10 and IL-6, a decrease in IFN $\gamma$ production but no change in IL-1 $\beta$ or TNF $\alpha$ production as determined by cytokine ELISA (Mascarucci et al. 2001).

\section{Aging and Adaptive Immunity}

One of the most striking features of immune senescence is the loss of naive T cells, believed to be largely due to diminished thymic output, increased homeostatic proliferation, and life-long exposure to pathogens, culminating in conversion of a large proportion of naive $\mathrm{T}$ cells into memory $\mathrm{T}$ cells (Czesnikiewicz-Guzik et al. 2008). The shift towards memory $\mathrm{T}$ cells results in a reduced diversity of the $\mathrm{T}$ cell repertoire, which is exacerbated by the appearance of T cell clonal expansions (TCE) and a reduced CD4/CD8 T cell ratio (Pawelec et al. 2010), with senescent CD8+ T-cells containing high levels of TNF $\alpha$. Similarly, rhesus macaques experience a progressive loss of naive $\mathrm{T}$ cells and a concomitant increase of memory $\mathrm{T}$ cells, especially $\mathrm{CD} 8^{+} \mathrm{CD} 28^{-}$effector memory (EM) $\mathrm{T}$ cells, as well as the accumulation of TCE, all of which correlate with a narrowing of the T cell repertoire (Fig. 2; Haberthur et al. 2010). Additionally, the frequency of naive T cells is inversely correlated to the frequency of $\mathrm{T}$ cell clonal expansions in aged monkeys (Cicin-Sain et al. 2007). As shown in humans, thymic involution, decreased lymphopoeisis in the bone marrow, and increased naive $\mathrm{T}$ cell turnover in aged rhesus macaques significantly contribute to the depletion of naive T cell reserves (Cicin-Sain et al. 2007). The accumulation of memory $\mathrm{T}$ cell is accompanied by increased frequency of IFN $\gamma$ and $\mathrm{TNF} \alpha$-secreting $\mathrm{T}$ cells primarily among the terminally differentiated CD8 ${ }^{+}$memory T cells (Jankovic et al. 2003).

Cytomegolovirus (CMV) infection has been associated with the accumulation of memory T cells (especially CD8 T cells) that have lost their CD28 expression in the elderly (Koch et al. 2007). Moreover, increased frequencies of CD28- cells have been linked to poor immune responses to influenza vaccines and increased inflammation (Trzonkowski et al. 2003). In addition, $\mathrm{CMV}^{\text {pos }}$ individuals only showed an increased in IFN $\gamma$ production with age, whereas $\mathrm{CMV}^{\text {neg }}$ young and middle-aged individuals showed increased production of IL-2, IL-4, and IFN $\gamma$ with age (Almanzar et al. 2005). Interestingly, young and aged macaques exhibit similar frequencies of rhesus CMV-specific CD4 and CD8 T cells, identical capabilities of producing IFN $\gamma, \mathrm{TNF} \alpha$, and IL-2 and equivalent responses to RhCMV re-infection (Cicin-Sain et al. 2011). These data imply a lack of age-related decline in RhCMV immunity with age.

Aging is associated with a decline in B cell function and an impairment of the antibody response. This decline is attributed to age-related reduction in CD4 $\mathrm{T}$ cell help as well as significant intrinsic changes within the B cell compartment (Ademokun et al. 2010). It is widely accepted that B cell numbers decline with age (Ademokun et al. 2010). There is also some evidence that aging results in the accumulation of memory B cells at the expense of naïve B cells (Ademokun et al. 2010). Regardless of changes in subset frequency, aging is accompanied by a 
significant decrease in the B cell repertoire diversity, which correlates strongly with frailty (Gibson et al. 2009). B cell homeostasis in NHPs has not been widely investigated, but recent studies indicate that similar to what has been observed in older humans, aged rhesus macaques ( $>18$ years old) have fewer circulating B cells in peripheral blood than adult animals (5-10 years old) and that the frequency of antigen experienced CD27+ (memory and marginal-zone like) B cells increases with age (Fig. 2; Haberthur et al. 2010).

\section{Response to Vaccination and Infection}

Age-related changes in innate and adaptive immunity lead to reduced immune response to infection and vaccination in humans, which in turn contribute to increased morbidity and mortality from infectious diseases (Weinberger et al. 2008). This age-related increase in susceptibility to infection is remarkably apparent in infectious diseases such as influenza, pneumonia, severe acute respiratory syndrome (SARS), and West Nile Virus (WNV) where most of the patients who succumbed to infection were $>50$ years of age (Chen et al. 2005; Simonsen et al. 2000; Fein 1999; Campbell et al. 2002). Moreover, older subjects are at increased risk of reactivation of latent pathogens such as varicella zoster virus (VZV), which causes Herpes Zoster (Shingles) (Insinga et al. 2005).

As described for humans, aged rhesus macaques generate a reduced $\mathrm{T}$ and $\mathrm{B}$ cell response to several pathogens compared to young animals. For instance, the decreased CD8 T cell responses in aged macaques to modified vaccinia Ankara correlated with the severity of naïve T cell loss (Cicin-Sain et al. 2010). Aged macaques infected with the H1N1 virus showed higher viral loads and higher expression of genes associated with inflammation and innate responses in the bronchoalveloar lavage (BAL) (Josset et al. 2012). Moreover, despite higher T cell proliferation in the BAL, antigen-specific $\mathrm{T}$ cell responses were delayed and reduced in magnitude. Aged Cynomolgous macaques are also more susceptible to SARS$\mathrm{CoV}$ infection than young adults and experienced increased multifocal pulmonary consolidation, alveolar damage, and proinflammatory responses despite comparable viral titers. Gene expression studies revealed that Type I interferons were reduced in the aged monkeys, and indeed, treatment of aged macaques with type I interferon reduced disease severity (Smits et al. 2010). Similarly, aged African green monkeys showed reduced frequency and proinflammatory cytokines production by peripheral lymphocytes (primarily CD8 T cells, and B cells), and lung leukocytes during SARS-CoV infection compared to young animals (Clay et al. 2014). Additional studies demonstrated that aged nonhuman primates infected with a primate homologue of human VZV, simian varicella virus (SVV), failed to clear SVV viremia despite comparable IgG antibody response (Meyer et al. 2013). In contrast, $\mathrm{SVV}$-specific $\mathrm{T}$ cell responses were significantly delayed compared to those generated by young animals, suggesting that, as described for VZV, age-related defects in $T$ cell responses result in poor control of varicella virus replication and dissemination. SVV also failed to establish latency in ganglia of aged rhesus macaques (Meyer et al. 2013). Studies using aged rhesus macaques also provided insight into why 
chikungunya virus (CHIKV) causes increased morbidity and mortality in the elderly (Pardigon 2009). Specifically, persistent CHIKV infection was linked to reduced T and B cell responses (Messaoudi et al. 2013). Therefore, infectious studies using young and aged rhesus macaques provide a unique opportunity to: (1) identify age-related differences impact the host immune responses and (2) determine how these differences the aged animal's ability to control microbial replication. In contrast to the studies described above, aged rhesus macaques showed no clinical disease following infection with $\mathrm{WNV}$ despite reduced $\mathrm{T}$ cell proliferation (Wertheimer et al. 2010). These studies are a reminder that NHP models may not be appropriate to evaluate mechanisms underlying age-related defects in host response to all human pathogens.

In addition to poor responses to vaccination, older individuals generate lower responses to vaccination. For example, following influenza vaccine $41-58 \%$ of persons 60-74 years of age generate antibodies compared to $90 \%$ in healthy adults (18-45 years old) (Goodwin et al. 2006). Moreover, the efficacy of the Shingles vaccine negatively correlates with age (Oxman et al. 2005). Similarly, several studies have reported diminished immune response to vaccination in aged macaques. For instance, lymphocyte proliferation and antibody production to tetanus toxoid vaccination were reduced in older monkeys, especially males (Haberthur et al. 2010). Another study showed a compromised mucosal immune response following cholera toxin vaccination (Taylor and Daniels 1992). Influenza vaccination of old rhesus monkeys results in a significantly lower antibody response than in young monkeys; however, a booster vaccine results in antibody titer at comparable levels to the young monkeys (Coe et al. 2012). Therefore, aged rhesus macaques provide a great platform to test the immunogenicity and efficacy of novel vaccine strategies. For instance, aged animals vaccinated with adjuvant cationic lipid/DNA complex show enhanced immunogenicity and significantly lower viral titers post challenge relative to controls (Carroll et al. 2014). In addition, influenza virus antibody titers in these vaccinated aged macaques had similar antibody titers as juvenile macaques who received the inactivated influenza vaccine, Fluzone ${ }^{\circledR}$, without an adjuvant (Carroll et al. 2014). In contrast to these findings, one study found that aged (19-24 years old) baboons generated a more robust antibody response to a Yersinia antigen than young baboon (Stacy et al. 2008). One possible explanation for the difference in outcome is that this study used 2-year-old animals with a potentially immature immune system as young controls, while previous studies used adult animals (10-year-old macaques).

\section{Rejuvenation of the Immune System}

In the past few years, several strategies to improve immune response to vaccination in the elderly have been explored, including the development of new adjuvants, different vaccination schedules, and new antigens. Parallel studies investigating immune senescence and testing interventions aimed at delaying/reversing age-related changes in immune function in NHP models, especially rhesus macaques, has increased (Nikolich-Zugich 2007). 


\section{Caloric Restriction}

Several studies have demonstrated that caloric restriction (CR) delays the aging process in several short-lived species such as rodents, worms, and yeast. In rodents, CR preserved frequency of naïve T cells, maintained T cell proliferative capacity by enhancing apoptosis of senescent cells, and improved the T cell response to influenza (Nikolich-Zugich and Messaoudi 2005). CR also reduced the levels of circulating IL-6 and TNF $\alpha$ and incidence of cancer (Nikolich-Zugich and Messaoudi 2005). Several epidemiological studies strongly suggested that CR could have similar benefits in humans (Roberts and Schoeller 2007; Willcox et al. 2007). To address this question, studies in macaques were initiated at the National institute on Aging (Mattison et al. 2012) as well as the Wisconsin National Primate Research Center (Colman et al. 2009). Reports from both studies showed that CR exerted many of the beneficial physiological effects observed in rodents (Cefalu et al. 1999; Lane et al. 1999).

The initiation of CR during early adulthood (adult-onset CR, AO-CR, 5-7 years) resulted in higher frequencies of naive $\mathrm{T}$ cells, a more diverse $\mathrm{T}$ cell repertoire, increased $\mathrm{T}$ cell proliferative capacity, and reduced the frequency of memory $\mathrm{T}$ cells that secreted the pro-inflammatory factors IFN $\gamma$ and $\mathrm{TNF} \alpha$ in response to CD3 stimulation in both male and female rhesus macaques (Messaoudi et al. 2006). AO-CR was also shown to reduce the steady-state plasma levels of IL-6 in rhesus macaques (Kim et al. 1997), as well as IL-6, IL-1 $\beta$, and IL-8 production by PBMC following LPS stimulation or induction of oxidative damage (Kim et al. 1997). In contrast to these results, an earlier study found that CR did not impact IL-6 secretion by PBMC following LPS stimulation in male rhesus macaques (Mascarucci et al. 2002). The discrepancies between the two data sets could be due to differences in the age of the animals at $\mathrm{CR}$ onset and the duration of CR.

In contrast to $\mathrm{AO}-\mathrm{CR}$, juvenile-onset $\mathrm{CR}$ (JO-CR) in male rhesus macaques resulted in a significant increase in the frequency of terminally differentiated memory CD4 and CD8 T cells and the reduction of T cell repertoire diversity. Furthermore, JO-CR increased the frequency of CD4 and CD8 T cells that secreted IFN $\gamma$ and $\mathrm{TNF} \alpha$ in response to $\mathrm{CD} 3$ stimulation and reduced $\mathrm{T}$ cell proliferative capacity. Similarly, late-onset ( $>17$ years of age) $\mathrm{CR}$ resulted in reduced $\mathrm{T}$ cell proliferative response to stimulation (Messaoudi et al. 2008). Taken together, these data strongly suggest there is an optimal window for the initiation of CR. More specifically, it appears that adult-onset CR could improve immunity, whereas juvenile or aged onset of dietary restriction would be expected to result in a diminished immune response to infection or vaccination.

\section{Cytokine Therapy}

Studies conducted in rodents identified IL-7 and IL-15 as key players in T cell homeostasis (Surh and Sprent 2008). Since the loss of naive T cells and accumulation of memory T cells are the most striking features of immune senescence, effort is 
aimed at delaying and/or reversing the loss of naive $\mathrm{T}$ cells while reducing the accumulation of effector memory T cells, through the manipulation of the IL-7 and IL-15 networks. The administration of recombinant rhesus IL-7 to young rhesus macaques leads to proliferation of naive and central memory CD4 and CD8 T cells (Picker et al. 2006). Moreover, treatment of SIV-infected young rhesus macaques with IL-7 increased absolute numbers of naive CD4 and CD8 T cells, as well as T cell activation and proliferation, which is likely due to an increase in thymic function (Nugeyre et al. 2003). These and other findings suggest that IL-7 may be a key player in rejuvenating the aged immune system. Indeed, the administration of recombinant IL-7 to aged rhesus macaques increased thymic output (Aspinall et al. 2007). However, IL-7 treatment produced no change in the frequency of naive T cells (Aspinall et al. 2007), indicating a rapid conversion of recent thymic emigrants to central memory $\mathrm{T}$ cells as indicated by a transient increase in the number of circulating CD4 and CD8 T cell (Aspinall et al. 2007). Furthermore, IL-7-treated aged female rhesus macaques generated a higher antibody response following vaccination with influenza compared to nontreated animals (Aspinall et al. 2007). However, the antibody titer eventually decreased to the same set point as that observed in control animals. While preliminary findings suggest a promising role for IL-7 treatment, the optimal schedule of administration and dosage remain to be determined.

As stated earlier, aging is accompanied by an increase in the frequency of EM T cells, especially CD8 EM T cells. In addition to contributing to the age-related increase in inflammatory cytokine production, the frequency of EM T cells is correlated with a decreased response to vaccination (Almanzar et al. 2005). Thus, reducing the frequency of circulating EM T cells could potentially alleviate chronic degenerative diseases associated with inflammation and improve responses to vaccination. IL-15 is important in the homeostasis and maintenance of the CD8 EM population (Surh and Sprent 2008). In fact, following treatment with neutralizing anti-IL-15 antibody, rheumatoid arthritis synovial membrane cell cultures from RA patients exhibit a $51 \%$ reduction in the release of TNFo, a $37 \%$ reduction in IL-6 production, and an $82 \%$ reduction in the release of IL-1 $\beta$ (Andersson et al. 2008). Anti-IL-15 antibody treatment has not been investigated in the context of immune senescence but will likely be a promising area of intervention that can be explored in the NHP model.

\section{Hormone Replacement Therapy}

Sex hormones have been shown to modulate immune function. Specifically, women are more susceptible to autoimmune diseases (Whitacre et al. 1999), generate stronger antibody responses to infection and vaccination (Giefing-Kroll et al. 2015), and are less susceptible to bacterial infection and sepsis following trauma or surgery than men (Wichmann et al. 2000). These observations suggest that the loss of ovarian steroids during menopause could contribute to immune senescence. Indeed, surgical menopause results in a decreased CD4/CD8 ratio, an increase in the 
percentage of NK cells, and a decrease in circulating B cells (Kumru et al. 2004). On the other hand, postmenopausal women receiving hormone therapy (HT) exhibit decreased plasma levels of the inflammatory factors TNF $\alpha$, IFN $\gamma$, and IL-6 (Vural et al. 2006) and lower production of inflammatory cytokines by T cells after antiCD3 stimulation (Engelmann et al. 2016). HT increases the absolute numbers of CD4 cells, B cells, and NK cells, in addition to increasing $\mathrm{T}$ cell proliferative capacity (Kumru et al. 2004; Porter et al. 2001). Since female NHPs have a 28-day menstrual cycle and undergo menopause, they offer a robust model to determine the ability of HT to reverse immune senescence. Surgical menopause results in altered $\mathrm{T}$ cell homeostasis and diminished immune response to vaccination in adult and aged female rhesus macaques (Engelmann et al. 2011). HT can partially rescue the decreased response to vaccination in aged female rhesus macaques (Engelmann et al. 2011). To address the caveats associated with surgical menopause, a novel NHP model of reduced ovarian reserve was developed where a biodegradable fiber containing 4-vinlycyclohexene diepoxide (VCD) is placed next to the ovaries (Appt et al. 2010). The VCD model will undoubtedly provide a unique opportunity to refine the timing, type, and duration of HT regimens.

In men, increasing age is associated with highly attenuated levels of bioactive androgens, especially testosterone and dehydroepiandrosterone (DHEA) (Harman et al. 2001). This phenomenon is termed andropause and is believed to contribute to perturbation in sleep-wake cycles, sarcopenia, osteoporosis, cardiovascular disease, and diabetes (Travison et al. 2009). The effects of androgens on the immune system remain controversial. Previous studies show that androgen ablation in mice and patients with prostate cancer results in increased $\mathrm{T}$ and $\mathrm{B}$ cell output (Ellis et al. 2001; Sutherland et al. 2005). In addition, pharmacological castration results in a reduced frequency of regulatory $\mathrm{T}$ cells (Treg) in young men (Page et al. 2006). These observations suggest that androgens may suppress lymphopoiesis and increased regulatory $\mathrm{T}$ cell frequencies. However, androgen supplementation in hypogonadal men reduces plasma levels of TNF $\alpha$ and IL-1 $\beta$, while increasing those of regulatory cytokine IL-10 (Malkin et al. 2004). Moreover, pharmacological castration reduces IFN $\gamma$ production by CD8 T cells (Page et al. 2006), suggesting that hypogonadism leads to increased inflammation and reduced $\mathrm{T}$ cell cytokine responses, both hallmarks of immune senescence. In addition, several studies have demonstrated that testosterone supplementation in older men exerts several benefits ranging from improved spatial cognition (Cherrier et al. 2005a) and cognitive function (Cherrier et al. 2005b) to increased muscle mass (Page et al. 2005) and bone density (Villareal et al. 2000) and decreased severity of cardiovascular disease (Webb et al. 1999a, b). Since male rhesus macaques also experience an age-related decline in circulating testosterone and DHEA levels as well as a marked attenuation of their circadian plasma profiles (Urbanski and Sorwell 2012), they provide a robust and pragmatic animal model in which to investigate the interplay between androgen supplementation and immune senescence. 


\section{Keratinocyte Growth Factor}

Another intervention aimed at rejuvenating the thymus is the administration of human keratinocyte growth factor (KGF), which stimulates production and differentiation of epithelial cells in a variety of tissues, including the thymus (Alpdogan et al. 2006). Early studies in rodents established that KGF treatment prior to allogenic bone marrow transplantation protects thymic epithelial cells from irradiation, leading to enhanced thymopoeisis and accelerated reconstitution of the peripheral T cells compartment in young and old mice (Min et al. 2002). Moreover, KGF supplementation improved T cell-dependent antibody responses in aged mice (Min et al. 2007). These data prompted studies involving NHPs to evaluate the ability of KGF to promote thymic regeneration following irradiation and stem cell transplantation. The results show that KGF-treated macaques have a well-preserved thymic structure and output translating into a broader T cell repertoire and improved antibody responses compared to control animals (Seggewiss et al. 2007). KGF-treated rhesus macaques demonstrated an increase in naive CD4 and CD8 T cell frequency, and this improvement was more pronounced in animals that had been given multiple KGF doses (Seggewiss et al. 2007). Interestingly, animals that received multiple doses of KGF also had the lowest levels of $\mathrm{T}$ cell homeostatic proliferation, which in turn resulted in a decreased conversion of naive to memory $\mathrm{T}$ cells.

\section{Thymosin}

Thymosin alpha $1(\mathrm{~T} \alpha 1)$ is one of several polypeptide hormones secreted by the thymus that controls the maturation of T cells, and has been investigated as a possible solution for the decreased immune function observed in the elderly. In early NHP studies, female rhesus macaques (18-25 years old) were vaccinated against tetanus toxoid and then treated with T $\alpha 1$ or placebo (Ershler et al. 1988). Although an increase in lymphocyte proliferation and NK cell cytotoxic activity was observed in T $\alpha 1$-treated animals, no significant effect on antibody response to the tetanus vaccine was observed (Ershler et al. 1988). However, encouraged by the increased lymphocyte proliferation, $T \alpha 1$ was then tested as an adjuvant to influenza vaccination in individuals aged 65 years and older (Ershler et al. 2007). Among patients receiving T $\alpha 1$ following influenza vaccination, $69 \%(31 / 45)$ had a fourfold increase in influenza antibody titers compared to $52 \%(21 / 40)$ of the placebo group. In a second trial by the same group involving 330 elderly volunteers, only a modest reduction in the number of influenza cases in the presence of T $\alpha 1$ was observed, but those who developed influenza displayed only mild or nonexistent symptoms compared to the placebo group (Ershler et al. 2007), implying that T $\alpha 1$ treatment might attenuate disease severity. These findings highlight the potential benefits of T $\alpha 1$ and suggest a need to revisit the possibility of using T $\alpha 1$ as an adjuvant for vaccination. 


\section{Conclusion and Future Directions}

According to data from the US Census Bureau, the number of older individuals aged 65 and over has increased significantly in most countries and is projected to accelerate in the coming decades. With great strides accomplished in increased life expectancy, efforts must now be directed at improving the health span ( $\mathrm{He}$ et al. 2016). One of the causes for morbidity and mortality among the elderly population is increased susceptibility to infectious diseases, due to dysregulated immunity often referred to as immunosenescence. NHPs, especially rhesus macaques, can play an invaluable role in understanding the mechanisms of immune senescence in addition to testing interventions and novel vaccination strategies in the elderly. Several gaps in our understanding of immune senescence in rhesus macaques still exist. For example, data on age-associated changes in innate immunity, B cell compartment, and microbiome in rhesus macaques are limited. Other future directions include the development of improved vaccination strategies better suited for the elderly, identification of biomarkers of aging, and rejuvenation methods to reverse immune senescence. Moreover, because NHPs are robust models for studying age-related increase in susceptibility to infection, they can be utilized to test the efficacy of interventions aimed at alleviating non-AIDS-related comorbidities in a growing HIV positive older population. In summary, a better understanding of immune dysregulation in an aged rhesus macaque model will establish the foundation to prevent and treat age-related disorders, thereby improving health span.

\section{References}

Ademokun A, Wu YC, Dunn-Walters D (2010) The ageing B cell population: composition and function. Biogerontology 11(2):125-137

Agrawal A et al (2009) Increased reactivity of dendritic cells from aged subjects to self-antigen, the human DNA. J Immunol 182(2):1138-1145

Aldebert D et al (2007) Differences in circulating dendritic cell subtypes in peripheral, placental and cord blood in African pregnant women. J Reprod Immunol 73(1):11-19

Almanzar $G$ et al (2005) Long-term cytomegalovirus infection leads to significant changes in the composition of the CD8+ T-cell repertoire, which may be the basis for an imbalance in the cytokine production profile in elderly persons. J Virol 79(6):3675-3683

Almeling L et al (2016) Motivational shifts in aging monkeys and the origins of social selectivity. Curr Biol 26(13):1744-1749

Alpdogan $\mathrm{O}$ et al (2006) Keratinocyte growth factor (KGF) is required for postnatal thymic regeneration. Blood 107(6):2453-2460

Alter G, Altfeld M (2009) NK cells in HIV-1 infection: evidence for their role in the control of HIV-1 infection. J Intern Med 265(1):29-42

Andersson AK, Feldmann M, Brennan FM (2008) Neutralizing IL-21 and IL-15 inhibits pro-inflammatory cytokine production in rheumatoid arthritis. Scand J Immunol 68(1):103-111

Ansari AA et al (2004) Use of recombinant cytokines for optimized induction of antiviral immunity against SIV in the nonhuman primate model of human AIDS. Immunol Res 29(1-3):1-18

Appt SE et al (2010) Experimental induction of reduced ovarian reserve in a nonhuman primate model (Macaca fascicularis). Comp Med 60(5):380-388

Arstila TP et al (2000) Diversity of human alpha beta T cell receptors. Science 288(5469):1135 
Aspinall R et al (2007) Old rhesus macaques treated with interleukin-7 show increased TREC levels and respond well to influenza vaccination. Rejuvenation Res 10(1):5-17

Asquith $\mathrm{M}$ et al (2012) Age-dependent changes in innate immune phenotype and function in rhesus macaques (Macaca mulatta). Pathobiology of Aging \& Age-related Diseases 2012, 2:18052

Autissier P et al (2010) Immunophenotyping of lymphocyte, monocyte and dendritic cell subsets in normal rhesus macaques by 12-color flow cytometry: clarification on DC heterogeneity. J Immunol Methods 360(1-2):119-128

Bar-Or A et al (2001) Immunological memory: contribution of memory B cells expressing costimulatory molecules in the resting state. J Immunol 167(10):5669-5677

Bible JM et al (2003) IGHV1, IGHV5 and IGHV7 subgroup genes in the rhesus macaque. Immunogenetics 54(12):867-873

Bodkin NL et al (2003) Mortality and morbidity in laboratory-maintained Rhesus monkeys and effects of long-term dietary restriction. J Gerontol A Biol Sci Med Sci 58(3):212-219

Brosnan SF, Wilson BJ, Beran MJ (2012) Old World monkeys are more similar to humans than New World monkeys when playing a coordination game. Proc Biol Sci 279(1733):1522-1530

Campbell GL et al (2002) West Nile virus. Lancet Infect Dis 2(9):519-529

Caraux A et al (2010) Circulating human B and plasma cells. Age-associated changes in counts and detailed characterization of circulating normal CD138- and CD138+ plasma cells. Haematologica 95(6):1016-1020

Carroll TD et al (2014) Efficacy of influenza vaccination of elderly rhesus macaques is dramatically improved by addition of a cationic lipid/DNA adjuvant. J Infect Dis 209(1):24-33

Carter D et al (1999) CD56 identifies monocytes and not natural killer cells in rhesus macaques. Cytometry 37(1):41-91

Cefalu WT et al (1999) Influence of caloric restriction on the development of atherosclerosis in nonhuman primates: progress to date. Toxicol Sci 52(2 Suppl):49-55

Chen Q et al (2005) Case fatality rate of severe acute respiratory syndromes in Beijing. Biomed Environ Sci 18(4):220-226

Cherrier MM et al (2005a) Testosterone improves spatial memory in men with Alzheimer disease and mild cognitive impairment. Neurology 64(12):2063-2068

Cherrier MM et al (2005b) The role of aromatization in testosterone supplementation: effects on cognition in older men. Neurology 64(2):290-296

Choi EI, Reimann KA, Letvin NL (2008) In vivo natural killer cell depletion during primary simian immunodeficiency virus infection in Rhesus Monkeys. J Virol 82(13):6758-6761

Chung E et al (2005) Characterization of virus-responsive plasmacytoid dendritic cells in the rhesus macaque. Clin Diagn Lab Immunol 12(3):426-435

Cicin-Sain L et al (2007) Dramatic increase in naive T cell turnover is linked to loss of naive T cells from old primates. Proc Natl Acad Sci U S A 104(50):19960-19965

Cicin-Sain L et al (2010) Loss of naive T cells and repertoire constriction predict poor response to vaccination in old primates. J Immunol 184(12):6739-6745

Cicin-Sain L et al (2011) Cytomegalovirus-specific $\mathrm{T}$ cell immunity is maintained in immunosenescent rhesus macaques. J Immunol 187(4):1722-1732

Clay CC et al (2014) Severe acute respiratory syndrome-coronavirus infection in aged nonhuman primates is associated with modulated pulmonary and systemic immune responses. Immun Ageing 11(1):4

Clayton JB et al (2016) Captivity humanizes the primate microbiome. Proc Natl Acad Sci USA 113:10376-10381

Coe CL, Ershler WB (2001) Intrinsic and environmental influences on immune senescence in the aged monkey. Physiol Behav 73(3):379-384

Coe CL, Lubach GR, Kinnard J (2012) Immune senescence in old and very old rhesus monkeys: reduced antibody response to influenza vaccination. Age (Dordr) 34(5):1169-1177

Colman RJ et al (2009) Caloric restriction delays disease onset and mortality in rhesus monkeys. Science 325(5937):201-204

Crowley JE et al (2008) Homeostatic control of B lymphocyte subsets. Immunol Res 42(1-3): $75-83$ 
Czesnikiewicz-Guzik M et al (2008) T cell subset-specific susceptibility to aging. Clin Immunol 127(1):107-118

Daza-Vamenta R et al (2004) Genetic divergence of the rhesus macaque major histocompatibility complex. Genome Res 14(8):1501-1515

De Martinis $\mathrm{M}$ et al (2005) Inflamm-ageing and lifelong antigenic load as major determinants of ageing rate and longevity. FEBS Lett 579(10):2035-2039

Dombrecht EJ et al (2006) Influence of anti-tumor necrosis factor therapy (Adalimumab) on regulatory T cells and dendritic cells in rheumatoid arthritis. Clin Exp Rheumatol 24(1):31-37

Doxiadis GG et al (2007) MIC gene polymorphism and haplotype diversity in rhesus macaques. Tissue Antigens 69(3):212-219

Dyke B et al (1986) A demographic-analysis of the Wisconsin-Regional-Primate-Center Rhesus Colony, 1962-1982. Am J Primatol 10(3):257-269

Edwards AD et al (2003) Toll-like receptor expression in murine DC subsets: lack of TLR7 expression by CD8 alpha+ DC correlates with unresponsiveness to imidazoquinolines. Eur J Immunol 33(4):827-833

Ellis TM et al (2001) Alterations in peripheral B cells and B cell progenitors following androgen ablation in mice. Int Immunol 13(4):553-558

Engelmann $\mathrm{F}$ et al (2011) Accelerated immune senescence and reduced response to vaccination in ovariectomized female rhesus macaques. Age (Dordr) 33(3):275-364

Engelmann F et al (2016) impact of estrogen therapy on lymphocyte homeostasis and the response to seasonal influenza vaccine in post-menopausal women. PLoS One 11(2):e0149045

Ermert K et al (1995) The immunoglobulin kappa locus of primates. Genomics 25(3):623-629

Ershler WB et al (1988) Aging and immunity in non-human primates. II. Lymphocyte response in thymosin treated middle-aged monkeys. J Gerontol 43(5):B142-B146

Ershler WB, Gravenstein S, Geloo ZS (2007) Thymosin alpha 1 as an adjunct to influenza vaccination in the elderly: rationale and trial summaries. Ann N Y Acad Sci 1112:375-384

Fein AM (1999) Pneumonia in the elderly: overview of diagnostic and therapeutic approaches. Clin Infect Dis 28(4):726-729

Gibson KL et al (2009) B-cell diversity decreases in old age and is correlated with poor health status. Aging Cell 8(1):18-25

Giefing-Kroll C et al (2015) How sex and age affect immune responses, susceptibility to infections, and response to vaccination. Aging Cell 14(3):309-321

Goodwin K, Viboud C, Simonsen L (2006) Antibody response to influenza vaccination in the elderly: a quantitative review. Vaccine 24(8):1159-1169

Greenaway HY et al (2009) Extraction and characterization of the rhesus macaque T-cell receptor beta-chain genes. Immunol Cell Biol 87(7):546-553

Gubler DJ (2007) The continuing spread of West Nile virus in the western hemisphere. Clin Infect Dis 45(8):1039-1046

Haberthur K et al (2010) Immune senescence in aged nonhuman primates. Exp Gerontol 45(9): 655-661

Haberthur $\mathrm{K}$ et al (2014) Intrabronchial infection of rhesus macaques with simian varicella virus results in a robust immune response in the lungs. J Virol 88(21):12777-12792

Harman SM et al (2001) Longitudinal effects of aging on serum total and free testosterone levels in healthy men. Baltimore longitudinal study of aging. J Clin Endocrinol Metab 86(2):724-731

Harris LD et al (2010) Downregulation of robust acute type I interferon responses distinguishes nonpathogenic simian immunodeficiency virus (SIV) infection of natural hosts from pathogenic SIV infection of rhesus macaques. J Virol 84(15):7886-7891

He W, Goodkind D, Kowal P (2016) An aging world: 2015, U.S.C. Bureau, Editor. 2016. United States Census Bureau

Hein WR, Griebel PJ (2003) A road less travelled: large animal models in immunological research. Nat Rev Immunol 3(1):79-84

Hughes AL, Yeager M (1998) Natural selection and the evolutionary history of major histocompatibility complex loci. Front Biosci 3:d509-d516 
Insinga RP et al (2005) The incidence of herpes zoster in a United States administrative database. J Gen Intern Med 20(8):748-753

Jankovic V, Messaoudi I, Nikolich-Zugich J (2003) Phenotypic and functional T-cell aging in rhesus macaques (Macaca mulatta): differential behavior of CD4 and CD8 subsets. Blood 102(9):3244-3251

Jing $\mathrm{Y}$ et al (2009) Aging is associated with a numerical and functional decline in plasmacytoid dendritic cells, whereas myeloid dendritic cells are relatively unaltered in human peripheral blood. Hum Immunol 70(10):777-784

Josset L et al (2012) Increased viral loads and exacerbated innate host responses in aged macaques infected with the 2009 pandemic H1N1 influenza A virus. J Virol 86(20):11115-11127

Kaiko GE, Stappenbeck TS (2014) Host-microbe interactions shaping the gastrointestinal environment. Trends Immunol 35(11):538-548

Kato H et al (2006) Differential roles of MDA5 and RIG-I helicases in the recognition of RNA viruses. Nature 441(7089):101-105

Kennedy RC, Shearer MH, Hildebrand W (1997) Nonhuman primate models to evaluate vaccine safety and immunogenicity. Vaccine 15(8):903-908

Ketloy C et al (2008) Expression and function of Toll-like receptors on dendritic cells and other antigen presenting cells from non-human primates. Vet Immunol Immunopathol 125(1-2): $18-30$

Kim M-J et al (1997) Adult-onset energy restriction of Rhesus Monkeys attenuates oxidative stressinduced cytokine expression by peripheral blood mononuclear cells. J Nutr 127(12):2293-2301

Kim WK et al (2010) Monocyte heterogeneity underlying phenotypic changes in monocytes according to SIV disease stage. J Leukoc Biol 87(4):557-567

Koch S et al (2007) Cytomegalovirus infection: a driving force in human $\mathrm{T}$ cell immunosenescence. Ann N Y Acad Sci 1114:23-35

Koopman G et al (2005) Systemic mobilization of antigen presenting cells, with a chimeric Flt-3 and G-CSF receptor agonist, during immunization of Macaca mulatta with HIV-1 antigens is insufficient to modulate immune responses or vaccine efficacy. Vaccine 23(33):4195-4202

Kuhrt D et al (2010) Evidence of early B-cell dysregulation in simian immunodeficiency virus infection: rapid depletion of naive and memory B-cell subsets with delayed reconstitution of the naive B-cell population. J Virol 84(5):2466-2476

Kumru S, Godekmerdan A, Yilmaz B (2004) Immune effects of surgical menopause and estrogen replacement therapy in peri-menopausal women. J Reprod Immunol 63(1):31-38

La Gruta NL et al (2007) A question of self-preservation: immunopathology in influenza virus infection. Immunol Cell Biol 85(2):85-92

Lane MA, Ingram DK, Roth GS (1999) Calorie restriction in nonhuman primates: effects on diabetes and cardiovascular disease risk. Toxicol Sci 52(2 Suppl):41-48

Lanier L (2008) Up on the tightrope: natural killer cell activation and inhibition. Nat Immunol 9(5): 495-997

Link JM, Hellinger MA, Schroeder HW Jr (2002) The Rhesus monkey immunoglobulin IGHD and IGHJ germline repertoire. Immunogenetics 54(4):240-250

Lloyd-Price J, Abu-Ali G, Huttenhower C (2016) The healthy human microbiome. Genome Med $8(1): 51$

Mahnke YD et al (2013) The who's who of T-cell differentiation: human memory T-cell subsets. Eur J Immunol 43(11):2797-2809

Mahy $\mathrm{M}$ et al (2014) Increasing trends in HIV prevalence among people aged 50 years and older: evidence from estimates and survey data. AIDS 28(Suppl 4):S453-S459

Malkin CJ et al (2004) The effect of testosterone replacement on endogenous inflammatory cytokines and lipid profiles in hypogonadal men. J Clin Endocrinol Metab 89(7):3313-3318

Malleret B et al (2008) Effect of SIVmac infection on plasmacytoid and CD1c+ myeloid dendritic cells in cynomolgus macaques. Immunology 124(2):223-233

Margolin DH et al (2006) Germinal center function in the spleen during Simian HIV infection in Rhesus Monkeys. J Immunol 177(2):1108-1119 
Mascarucci P et al (2001) Age-related changes in cytokine production by leukocytes in rhesus monkeys. Aging (Milano) 13(2):85-94

Mascarucci P et al (2002) Cytokine responses in young and old Rhesus Monkeys: effect of caloric restriction. J Interf Cytokine Res 22(5):565-571

Mattison JA et al (2012) Impact of caloric restriction on health and survival in rhesus monkeys from the NIA study. Nature 489(7415):318-321

Mavilio D et al (2005) Identification of NKG2A and NKp80 as specific natural killer cell markers in rhesus and pigtailed monkeys. Blood 106(5):1718-1725

Messaoudi I et al (2006) Delay of $\mathrm{T}$ cell senescence by caloric restriction in aged long-lived nonhuman primates. Proc Natl Acad Sci U S A 103(51):19448-19453

Messaoudi I et al (2008) Optimal window of caloric restriction onset limits its beneficial impact on T-cell senescence in primates. Aging Cell 7(6):908-919

Messaoudi I et al (2013) Chikungunya virus infection results in higher and persistent viral replication in aged rhesus macaques due to defects in anti-viral immunity. PLoS Negl Trop Dis 7(7): 2343

Meyer C et al (2013) Age and immune status of rhesus macaques impact simian varicella virus gene expression in sensory ganglia. J Virol 87(15):8294-8306

Meyer $\mathrm{C}$ et al (2015) Impact of irradiation and immunosuppressive agents on immune system homeostasis in rhesus macaques. Clin Exp Immunol 181(3):491-510

Min D et al (2002) Protection from thymic epithelial cell injury by keratinocyte growth factor: a new approach to improve thymic and peripheral T-cell reconstitution after bone marrow transplantation. Blood 99(12):4592-4600

Min D et al (2007) Sustained thymopoiesis and improvement in functional immunity induced by exogenous KGF administration in murine models of aging. Blood 109(6):2529-2537

Nadon NL (2006) Of mice and monkeys: national Institute on Aging resources supporting the use of animal models in biogerontology research. J Gerontol A Biol Sci Med Sci 61(8):813-815

Neumann B et al (2015) Characterization of B and plasma cells in blood, bone marrow, and secondary lymphoid organs of rhesus macaques by multicolor flow cytometry. J Leukoc Biol 97(1):19-30

Nikolich-Zugich J (2007) Non-human primate models of T-cell reconstitution. Semin Immunol 19(5):310-317

Nikolich-Zugich J, Messaoudi I (2005) Mice and flies and monkeys too: caloric restriction rejuvenates the aging immune system of non-human primates. Exp Gerontol 40(11):884-893

Nugeyre MT et al (2003) IL-7 stimulates T cell renewal without increasing viral replication in simian immunodeficiency virus-infected macaques. J Immunol 171(8):4447-4453

O'Keeffe M, Mok WH, Radford KJ (2015) Human dendritic cell subsets and function in health and disease. Cell Mol Life Sci 72(22):4309-4325

Oxman MN et al (2005) A vaccine to prevent herpes zoster and postherpetic neuralgia in older adults. N Engl J Med 352(22):2271-2284

Page ST et al (2005) Exogenous testosterone (T) alone or with finasteride increases physical performance, grip strength, and lean body mass in older men with low serum T. J Clin Endocrinol Metab 90(3):1502-1510

Page ST et al (2006) Effect of medical castration on CD4+ CD25+ T cells, CD8+ T cell IFN-gamma expression, and NK cells: a physiological role for testosterone and/or its metabolites. Am J Physiol Endocrinol Metab 290(5):E856-E863

Panda A et al (2010) Age-associated decrease in TLR function in primary human dendritic cells predicts influenza vaccine response. J Immunol 184(5):2518-2527

Pardigon N (2009) The biology of chikungunya: a brief review of what we still do not know. Pathol Biol (Paris) 57(2):127-132

Pawelec G, Larbi A, Derhovanessian E (2010) Senescence of the human immune system. J Comp Pathol 142(Suppl 1):S39-S44

Phillips KA et al (2014) Why primate models matter. Am J Primatol 76(9):801-827 
Picker LJ et al (2006) IL-15 induces CD4 effector memory T cell production and tissue emigration in nonhuman primates. J Clin Invest 116(6):1514-1524

Pitcher CJ et al (2002) Development and homeostasis of T cell memory in rhesus macaque. J Immunol 168(1):29-43

Ponnappan S, Ponnappan U (2011) Aging and immune function: molecular mechanisms to interventions. Antioxid Redox Signal 14(8):1551-1585

Porter VR et al (2001) Immune effects of hormone replacement therapy in post-menopausal women. Exp Gerontol 36(2):311-326

Rathinam VA et al (2010) The AIM2 inflammasome is essential for host defense against cytosolic bacteria and DNA viruses. Nat Immunol 11(5):395-402

Rhesus Macaque Genome S et al (2007) Evolutionary and biomedical insights from the rhesus macaque genome. Science 316(5822):222-234

Roberts SB, Schoeller DA (2007) Human caloric restriction for retardation of aging: current approaches and preliminary data. J Nutr 137(4):1076-1077

Rogers J, Gibbs RA (2014) Comparative primate genomics: emerging patterns of genome content and dynamics. Nat Rev Genet 15(5):347-359

Roifman CM et al (2000) A partial deficiency of interleukin-7R alpha is sufficient to abrogate T-cell development and cause severe combined immunodeficiency. Blood 96(8):2803-2807

Ross CN et al (2012) Aging phenotypes of common Marmosets (Callithrix jacchus). J Aging Res 2012:567143

Salmon AB (2016) Moving toward 'common' use of the marmoset as a non-human primate aging model. Pathobiol Aging Age Relat Dis 6:32758

Seggewiss R et al (2007) Keratinocyte growth factor augments immune reconstitution after autologous hematopoietic progenitor cell transplantation in rhesus macaques. Blood 110(1): 441-449

Sender R, Fuchs S, Milo R (2016) Revised estimates for the number of human and bacteria cells in the body. PLoS Biol 14(8):e1002533

Shaw AC et al (2010) Aging of the innate immune system. Curr Opin Immunol 22(4):507-513

Shively CA, Clarkson TB (2009) The unique value of primate models in translational research. Am J Primatol 71(9):715-721

Simonsen L et al (2000) The impact of influenza epidemics on hospitalizations. J Infect Dis 181(3): $831-837$

Smits SL et al (2010) Exacerbated innate host response to SARS-CoV in aged non-human primates. PLoS Pathog 6(2):e1000756

Stacy $\mathrm{S}$ et al (2008) An age-old paradigm challenged: old baboons generate vigorous humoral immune responses to LcrV, a plague antigen. J Immunol 181(1):109-115

Sugimoto C et al (2015) Differentiation kinetics of blood monocytes and dendritic cells in Macaques: insights to understanding human myeloid cell development. J Immunol 195(4): 1774-1781

Surh CD, Sprent J (2008) Homeostasis of naive and memory T cells. Immunity 29(6):848-862

Sutherland JS et al (2005) Activation of thymic regeneration in mice and humans following androgen blockade. J Immunol 175(4):2741-2753

Tardif SD et al (2013) IACUC review of nonhuman primate research. ILAR J 54(2):234-245

Taylor L, Daniels C (1992) Ageing compromises gastrointestinal mucosal immune response in the rhesus monkey. Immunology 75(4):614-618

Teleshova $\mathrm{N}$ et al (2004a) CpG-C immunostimulatory oligodeoxyribonucleotide activation of plasmacytoid dendritic cells in rhesus macaques to augment the activation of IFN-gammasecreting simian immunodeficiency virus-specific T cells. J Immunol 173(3):1647-1657

Teleshova $\mathrm{N}$ et al (2004b) Short-term Flt3L treatment effectively mobilizes functional macaque dendritic cells. J Leukoc Biol 75(6):1102-1110

Thiel C, Bontrop RE, Lanchbury JS (1995) Structure and diversity of the T-cell receptor alpha chain in rhesus macaque and chimpanzee. Hum Immunol 43(2):85-94 
Tigges $\mathrm{J}$ et al (1988) Survival rate and life-span of Rhesus-Monkeys at the Yerkes-RegionalPrimate-Research-Center. Am J Primatol 15(3):263-273

Travison TG et al (2009) Temporal trends in testosterone levels and treatment in older men. Curr Opin Endocrinol Diabetes Obes 16(3):211-217

Trzonkowski P et al (2003) Association between cytomegalovirus infection, enhanced proinflammatory response and low level of anti-hemagglutinins during the anti-influenza vaccination - an impact of immunosenescence. Vaccine 21(25-26):3826-3836

Urbanski HF, Sorwell KG (2012) Age-related changes in neuroendocrine rhythmic function in the rhesus macaque. Age (Dordr) 34(5):1111-1121

VandeBerg JL, Williams-Blangero S (1997) Advantages and limitations of nonhuman primates as animal models in genetic research on complex diseases. J Med Primatol 26(3):113-119

Vassena L et al (2012) Treatment with IL-7 prevents the decline of circulating CD4+ T cells during the acute phase of SIV infection in rhesus macaques. PLoS Pathog 8(4):e1002636

Villareal DT, Holloszy JO, Kohrt WM (2000) Effects of DHEA replacement on bone mineral density and body composition in elderly women and men. Clin Endocrinol 53(5):561-568

Villinger F et al (2004) IL-15 is superior to IL-2 in the generation of long-lived antigen specific memory CD4 and CD8 T cells in rhesus macaques. Vaccine 22(25-26):3510-3521

Vural P, Akgul C, Canbaz M (2006) Effects of hormone replacement therapy on plasma pro-inflammatory and anti-inflammatory cytokines and some bone turnover markers in postmenopausal women. Pharmacol Res 54(4):298-302

Wang X et al (2008) Differential cross-reactivity of monoclonal antibody OPD4 (anti-CD45RO) in macaques. Dev Comp Immunol 32(7):859-868

Ward KW, Nagilla R, Jolivette LJ (2005) Comparative evaluation of oral systemic exposure of 56 xenobiotics in rat, dog, monkey and human. Xenobiotica 35(2):191-210

Webb CM et al (1999a) Effect of acute testosterone on myocardial ischemia in men with coronary artery disease. Am J Cardiol 83(3):437-439, A9

Webb CM et al (1999b) Effects of testosterone on coronary vasomotor regulation in men with coronary heart disease. Circulation 100(16):1690-1696

Webster RL, Johnson RP (2005) Delineation of multiple subpopulations of natural killer cells in rhesus macaques. Immunology 115(2):206-214

Wei C et al (2007) A new population of cells lacking expression of CD27 represents a notable component of the B cell memory compartment in systemic lupus erythematosus. J Immunol 178(10):6624-6633

Weinbauer GF et al (2008) Physiology and endocrinology of the ovarian cycle in Macaques. Toxicol Pathol 36(7S):7S-23S

Weinberger B et al (2008) Vaccines: biology of immune responses to vaccines in elderly persons. Clin Infect Dis 46(7):1078-1084

Weiskopf D, Weinberger B, Grubeck-Loebenstein B (2009) The aging of the immune system. Transpl Int 22(11):1041-1050

Wertheimer A et al (2010) Immune response to the West Nile virus in aged non-human primates. PLoS One 5(12):e15514

Whitacre CC, Reingold SC, O'Looney PA (1999) A gender gap in autoimmunity. Science 283(5406): 1277-1278

Wichmann MW et al (2000) Incidence and mortality of severe sepsis in surgical intensive care patients: the influence of patient gender on disease process and outcome. Intensive Care Med 26(2):167-172

Willcox BJ et al (2007) Caloric restriction, the traditional Okinawan diet, and healthy aging: the diet of the world's longest-lived people and its potential impact on morbidity and life span. Ann N Y Acad Sci 1114(1):434-455

Wong KL et al (2011) Gene expression profiling reveals the defining features of the classical, intermediate, and nonclassical human monocyte subsets. Blood 118(5):e16-e31

Yasuda K et al (2015) Biogeography of the intestinal mucosal and lumenal microbiome in the rhesus macaque. Cell Host Microbe 17(3):385-391 